\title{
Asymptomatic Evolution and Regression of Temporal Lobe Necrosis After Adjuvant Radiation for Skin Cancer: A Case Report and Review of Literature
}

\author{
Rima Pathak ${ }^{1}$, Gaurav Bahl ${ }^{2}$ \\ 1. Radiation Oncology, University of British Columbia, BC Cancer Agency 2. Division of Radiation \\ Oncology and Developmental Radiotherapeutics, University of British Columbia, BC Cancer Agency
}

$\square$ Corresponding author: Rima Pathak,drrimapathak@gmail.com

Disclosures can be found in Additional Information at the end of the article

\section{Abstract}

Temporal Lobe Necrosis (TLN) is not an expected complication of adjuvant radiation therapy (RT) for skin cancers and has become uncommon otherwise in daily practice due to improved RT planning and modern delivery techniques. TLN is a great mimic and can be mistaken for disease recurrence, metastasis to the brain, or high grade primary brain tumor. This case report demonstrates the importance of diagnosing the entity, its natural evolution, and dosimetric correlation with published constraints. It emphasizes the importance of thorough clinical examination on follow-up and review of previous radiation plan when encountered with challenging differentials. We also provide a review of clinical presentations, imaging modalities, and management options for patients with suspected TLN.

Categories: Radiation Oncology, Radiology

Keywords: temporal lobe necrosis, radiation therapy, skin cancer

\section{Introduction}

Radiation-induced temporal lobe necrosis (TLN) is an uncommon side effect usually associated with high doses of radiation for nasopharyngeal carcinoma (NPC), pituitary adenoma, and skull base tumors. It is however, not an expected complication of adjuvant radiation therapy (RT) for skin cancers. TLN has become uncommon in daily practice due to improved RT planning and modern delivery techniques.

Received 12/01/2015

Review began 01/12/2016

Review ended 01/17/2016

Published 02/05/2016

C Copyright 2016

Pathak et al. This is an open access article distributed under the terms of the Creative Commons Attribution License CC-BY 3.0., which permits unrestricted use, distribution, and reproduction in any medium, provided the original author and source are credited.
The incidence of TLN varies from $0 \%-24 \%$ with conventional fractionation to $35 \%$ with accelerated fractionation [1-3]. Brain tissue is known to be highly vulnerable to changes in dose fractionation and treatment times. The symptoms range from being asymptomatic to severe morbidity and frequently mortality. TLN is a great mimic and can be mistaken for disease recurrence, metastasis to the brain, or a high grade primary brain tumor. This case report demonstrates the importance of diagnosing the entity, its natural evolution and dosimetric correlation with published guidelines. Informed patient consent was obtained for this study.

\section{Case Presentation}

A 74-year-old male patient presented with a $1.5 \mathrm{~cm}$ ulcerated swelling over the skin of his left pinna in October 2008. Biopsy revealed an invasive moderately differentiated squamous cell carcinoma (MDSCC) which was excised with wide margins. In April 2009, he developed 
recurrent disease posterior to the angle of the mandible with regional metastasis to the parotid and suspicious involvement of ipsilateral level II neck nodes. A total parotidectomy with modified radical neck dissection was performed in May 2009. Pathology confirmed MDSCC in the parotid with positive margins. All dissected lymph nodes were negative. He received a hypofractionated course of adjuvant RT to the parotid region: $60 \mathrm{~Gy} / 25$ fractions (2.4 Gy per fraction, one fraction per day, five days per week). RT was planned with $6 \mathrm{MV}$ photons using a 5-field 3D conformal technique. He tolerated treatment reasonably well and completed treatment in September 2009 without interruptions.

At 18 months post-RT, a small patch of osteoradionecrosis was noted in the left external auditory canal. This was treated conservatively and it healed well. A follow-up head and neck computed tomography (CT) scan was done in June 2013 (Figure 1A), when his care was transferred to a new physician. This reported an incidental finding of an irregular enhancing focus involving the left temporal lobe and extending to left parietal lobe measuring about $8 \mathrm{x}$ $3.3 \mathrm{~cm}$ in size. It was associated with moderate white matter edema extending up to the periventricular location of the posterior horn of the lateral ventricle. The differential diagnoses were brain metastasis and subacute cerebral infarct. There was no evidence of recurrence in the post-op or irradiated region. The patient denied development of any new symptoms. However, his wife had noted some short term memory loss and occasional word-finding difficulty over the last few months. A clinical examination revealed a stable lower motor neuron facial palsy, which he had developed postoperatively in 2009. Neurological examination was otherwise unremarkable. 


\section{Cureus}

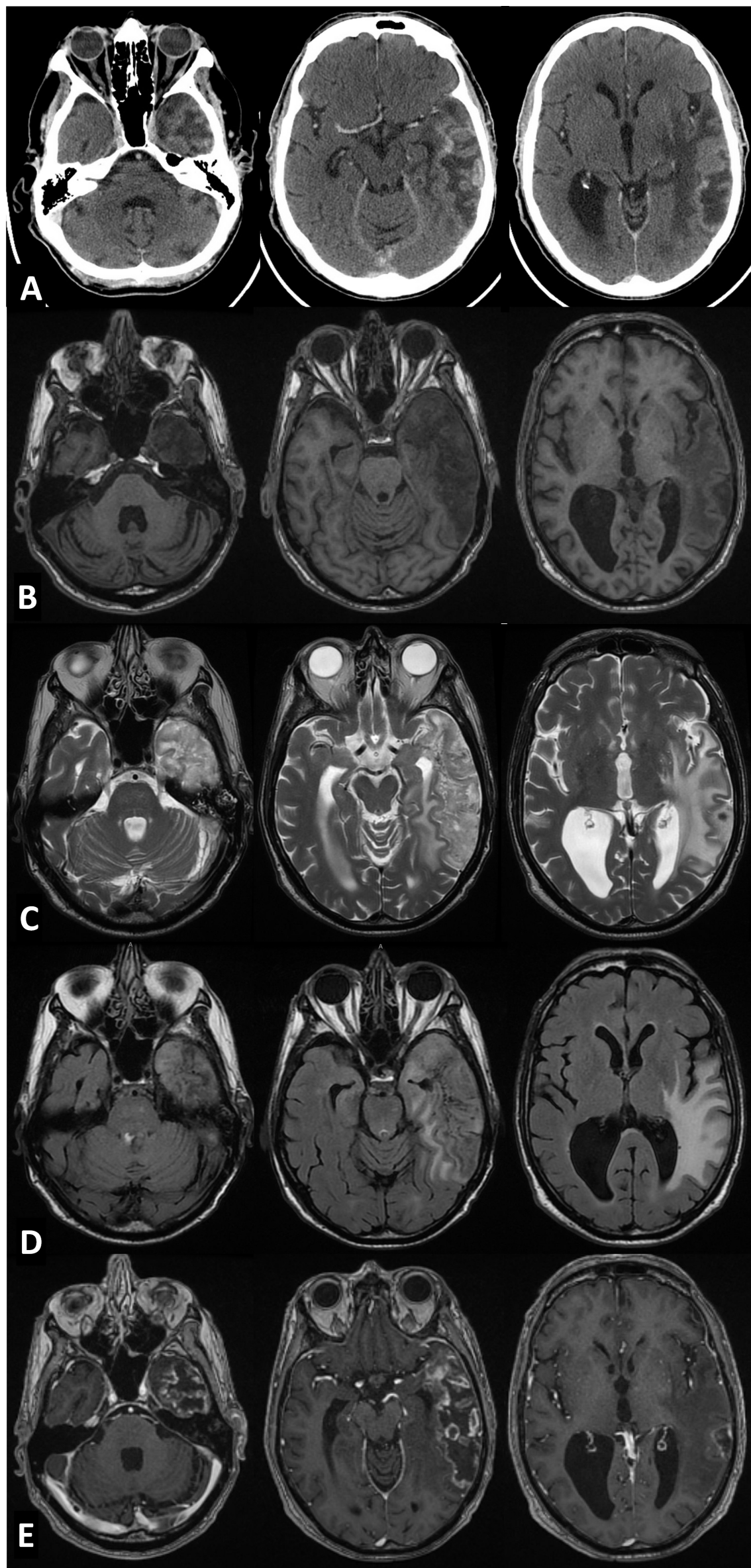

FIGURE 1: Incidental imaging findings of the patient 


\section{Cureus}

A- Enhancing lesion with central necrosis on contrast-enhanced CT scan. B- Hypo-intense lesion with effacement of temporal horn of the lateral ventricle on left side on T1 W images. CHyper-intense lesion with areas of cystic degeneration T2 W images. D- Extent of vasogenic edema seen on T2-FLAIR images. E- Ring enhancement with central necrosis on post contrast images.

A magnetic resonance imaging scan (MRI) of the brain (Figures $1 B-1 E$ ) revealed a heterogeneous mass with peripheral nodular enhancement and some areas of T2-weightedfluid-attenuated inversion recovery (T2/ FLAIR) signal hyperintensity. The surrounding vasogenic edema was seen reaching high parietal lobe superiorly and left hippocampus medially.

There was no evidence of abnormal restricted diffusion (Figures $2 F-2 G$ ). The differential diagnoses were revised to exclude subacute infarction and include radionecrosis or infection.

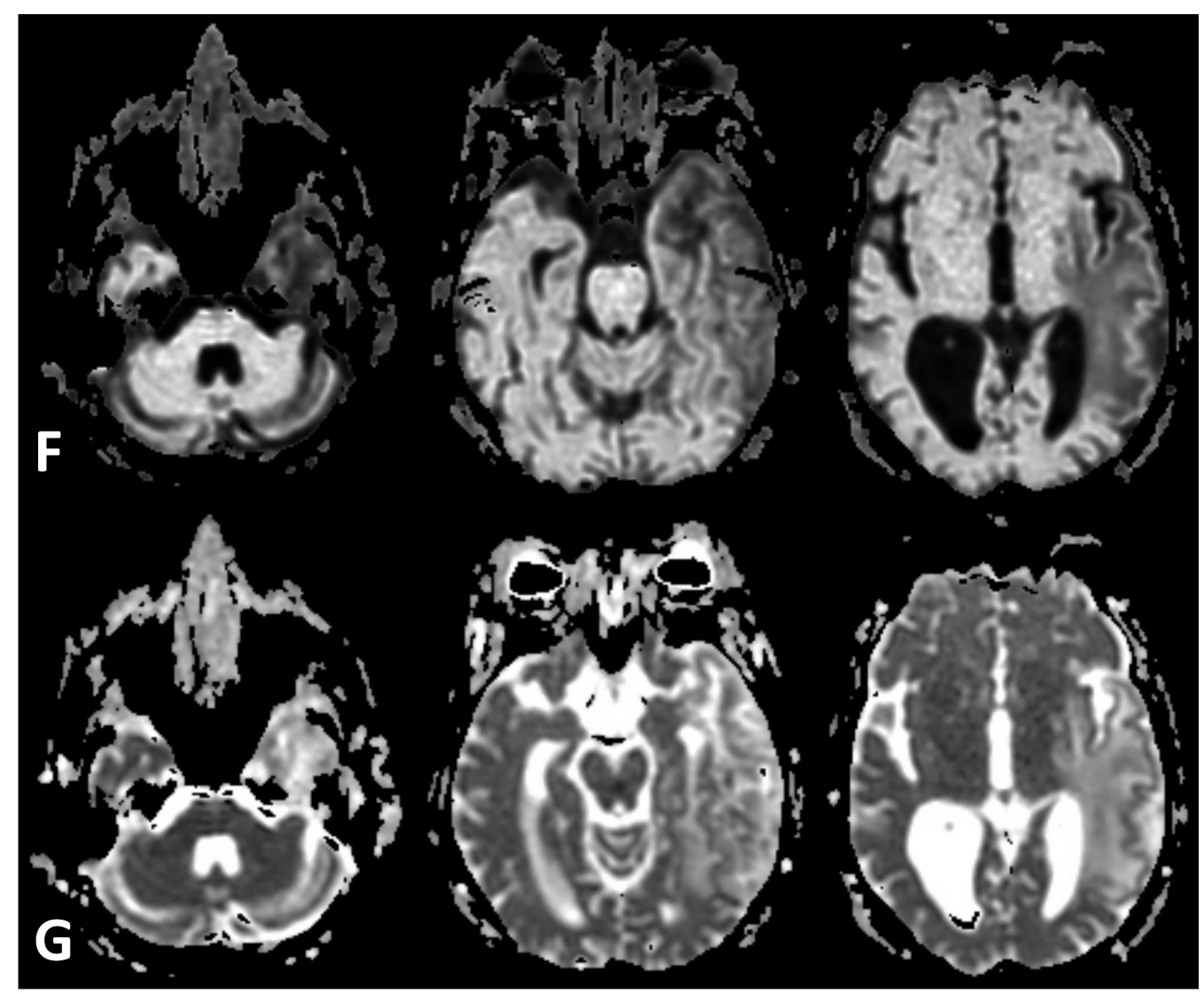

FIGURE 2: Diffusion weighted images for characterizing the lesion

F- No abnormal restriction of fluid noted on exponential apparent diffusion coefficient images eliminating T2 shine-through effect. G- No abnormal restriction of fluid noted on apparent diffusion coefficient images.

The radiation treatment plan was reviewed to rule out radionecrosis of the temporal lobe. The extent of the lesion in the temporo-parietal lobes correlated with the shape of the isodose 


\section{Cureus}

curves on the treatment planning system, and hence, radionecrosis of the temporal lobe was established as the working diagnosis (Figure $3 H$ ). As the patient was asymptomatic, it was decided to observe the natural evolution of this lesion with serial imaging and intervene early if any new signs or symptoms developed. Subsequent MRI at three months (Figure 4I) showed reduction in edema and mass effect; however, the enhancement remained unchanged. At nine months, the MRI showed a new well-defined sub-centimeter enhancing nodule in the contralateral para hippocampal cortex reported as progression of metastatic disease (Figure 4J). A neuroradiology consultation suggested that the lesion could be a part of the evolving radionecrosis; however, there remained a distinct possibility of it being metastasis. In view of the lack of new clinical signs or symptoms, we decided to continue observation. An imaging at 12 months revealed no change in the size or characteristics of either lesion.

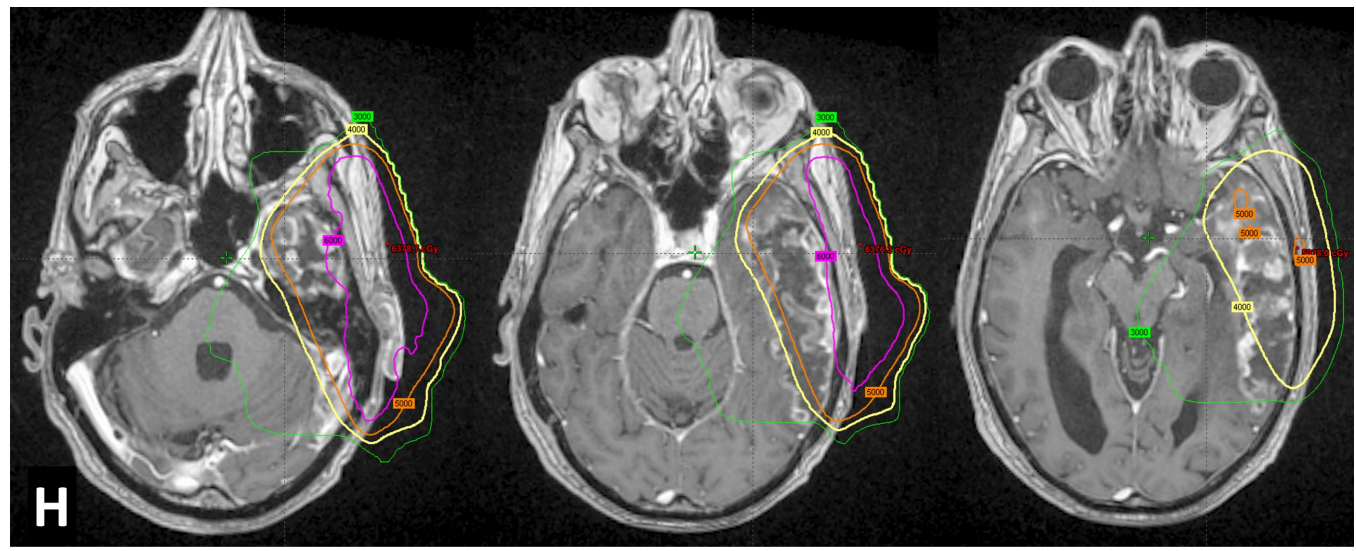

FIGURE 3: Super-imposition of treatment planning isodoses on the axial post contrast MRI images

$\mathrm{H}$ - Extent of temporal lobe necrosis following the $40 \mathrm{~Gy}$ isodose (yellow), 60 Gy isodose confines to the extracranial tissue (pink) and the lesion mostly encompassed by the 50 Gy isodose (orange). 


\section{Cureus}

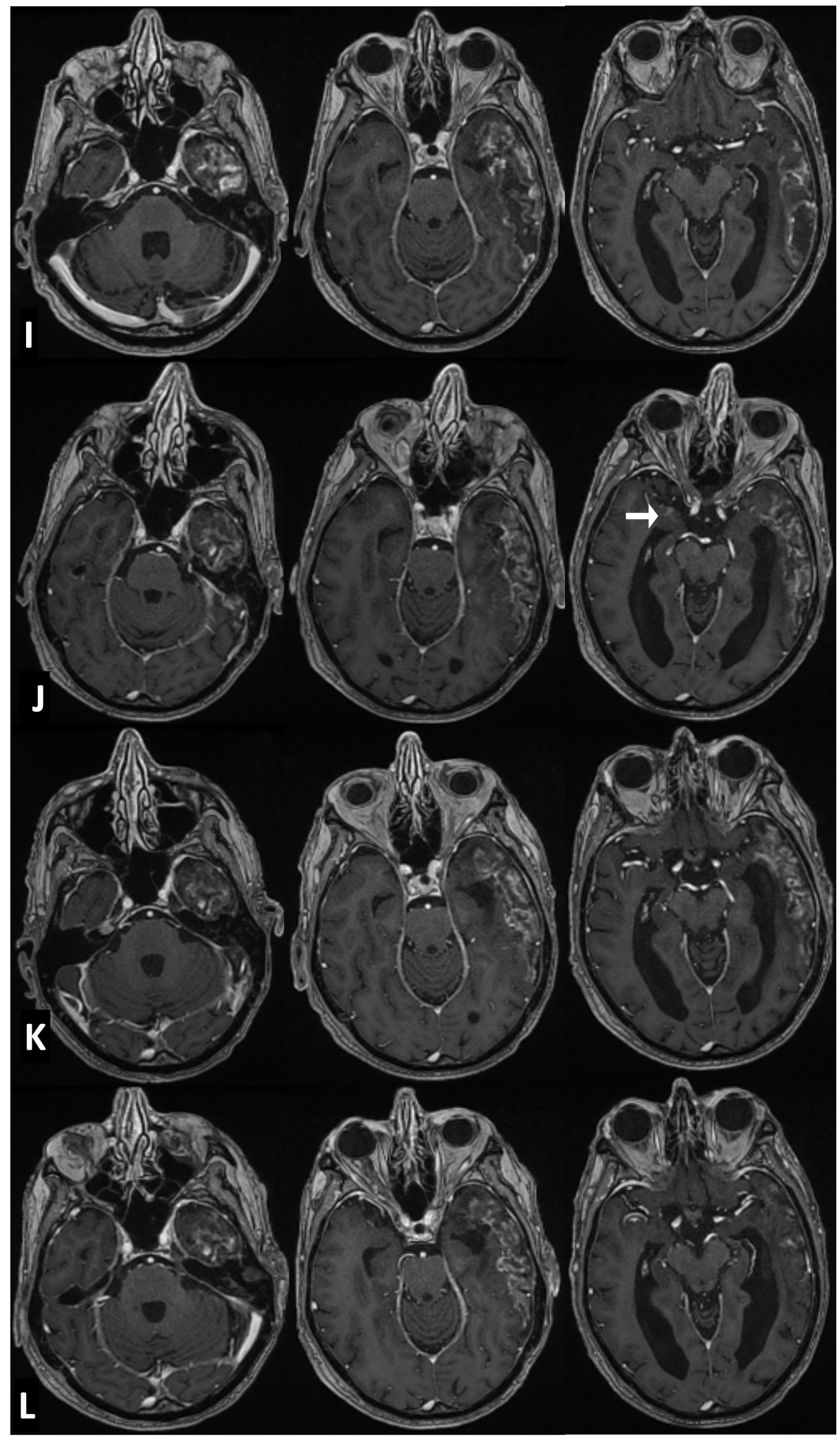

FIGURE 4: Follow-up axial post-contrast MRI images 
I- At three months, no change in enhancement. J- At nine months, development of new contralateral temporal lobe enhancing lesion (white arrow). K- At 18 months, mild temporal lobe atrophy with stable enhancement pattern in both the lesions. L- At 24 months encephalomalacia with ex-vacuo dilatation of the temporal horn and marked temporal lobe atrophy, resolution of contralateral enhancing lesion.

An MRI scan done in September 2014 reported that there was regression in the edema and T2/FLAIR changes but there was no change in the contralateral enhancing nodule (Figure $4 K$ ). An MRI scan at two years reported significant encephalomalacia with ex-vacuo dilatation of the temporal horn with loss of volume of the temporal lobe cortex and white matter (Figure $4 L$ ). The contralateral enhancing lesion had resolved. Throughout this follow-up period, the patient remained healthy and his clinical condition remained stable without any intervention. The patient remains well 30 months after the first suspicious CT.

\section{Discussion}

Temporal lobe necrosis is most commonly associated with radical RT for NPC and is rarely seen with other extracranial malignancies. Ironically, it was first described by Fisher and Holfelder after treatment for basal cell carcinoma of the temporal region in 1930 [4]. The temporal lobes have a variety of functions related to hearing, memory, visual perceptions, processing of semantics and complex inputs. Injury to one or both temporal lobes may present as problems with short-term memory, selective attention, recognizing faces, understanding spoken words or finding words (the only symptom in our patient). Severe injury to the amygdala in both the lobes could occur with treatment for skull base malignancies and may present with Kluver-Bucy Syndrome with symptoms like amnesia, hyperphagia, aggressive uninhibited sexual behaviour with persistent talking and visual agnosia. Vasogenic edema can result in symptoms of a mass effect, such as headaches, nausea, vomiting, photophobia, increased irritability, and diplopia. Necrosis and edema can lead to a hypercoagulable state resulting in thrombus formation and stroke. TLN has a variable latency period from three months to 13 years; however, most present within the first five years after completion of radiation therapy.

It is not uncommon to mistake TLN with a high-grade primary brain tumor, disease recurrence or brain metastasis. There are various imaging modalities that help in differentiating the above: MRI (diffusion-weighted imaging, spectroscopy, and perfusion), positron emission tomography (PET)-CT, and PET-MRI scan. Due to ease of availability, patients often first undergo a CT scan or an MRI. MRI features include white matter lesions that are predominantly hyperintense on T2-weighted images with thin-walled cystic areas. Vasogenic edema causes mass effect and gray matter changes like thinning of the cortex with irregular or blurred gray-white matter junction. A post-contrast scan shows typical swiss-cheese-, ring- or finger-like enhancement with surrounding hemosiderin deposition [5]. An MR spectroscopy usually reveals high lipid lactate peaks with low choline and $\mathrm{N}$-acetyl aspartate peaks. The necrotic tissue shows hypoperfusion on dynamic susceptibility contrast-enhanced MRI. In conjunction with perfusion, the apparent diffusion coefficient maps (no restriction) help in the diagnosis. A PETCT scan divides the radionecrosis into three different types depending on the stage of evolution: edema type, liquefactive necrosis type, and atrophic calcification type in that order [6]. For our patient, the strongest evidence came from the morphology and extent of the enhancing lesion and its correlation with the isodose distribution on the RT planning images. Hence, it was a valuable and inexpensive link to the diagnosis. As seen in Figure 3H, the enhancing and necrotic lesion follows the $40 \mathrm{~Gy}$ isodose line almost consistently. However, most of the affected brain tissue was enclosed by the $50 \mathrm{~Gy}$ isodose.

The treatment options for TLN include high doses of steroids in the early stages to control 


\section{Cureus}

edema and mass effect; anticoagulants, antiplatelets, and vitamins like alpha-tocopherol to prevent thrombus formation and stroke [7]. Some reports indicate that hyperbaric oxygen initiates cellular and vascular repair and may be beneficial [8]. Recently, bevacizumab has been used in patients and has resulted in improvement in imaging characteristics and neurocognitive deficits. The initial response to bevacizumab can be dramatic and may be utilized for confirmation of diagnosis in the absence of histological evidence [8]. Surgery is indicated for TLN as a palliative measure to reduce symptoms of mass effect and has the advantage of providing histopathological confirmation of diagnosis.

About $65 \%$ of radiation-therapy-related deaths from NPC occur due to TLN [3]. Despite aggressive therapy, this condition can be fatal, and hence, the focus should be on prevention. Many studies have emphasized the critical importance of fraction size, overall treatment time, and product of total dose and fraction size [3]. Table 1 shows various dose constraints for effectively preventing TLN based on retrospective studies [1-3, 9-15]. These vary from a maximum allowable dose as low as $45 \mathrm{~Gy}$ to as high as $69 \mathrm{~Gy}$. As fraction size has been found to be important, some recommendations are based on biological equivalent dose (BED) (with $\alpha / \beta$ ratio of two or three). Table 1 also compares the dosimetric parameters for our patient with recommended constraints from literature.

\begin{tabular}{|c|c|c|c|c|c|c|c|c|}
\hline Authors & $\begin{array}{l}\text { Number } \\
\text { n }\end{array}$ & $\begin{array}{l}\text { Tumor/Cancer } \\
\text { Type }\end{array}$ & $\begin{array}{l}\text { Suggested } \\
\text { Constraints }\end{array}$ & $\begin{array}{l}\text { End Point of } \\
\text { Temporal } \\
\text { Lobe } \\
\text { Necrosis }\end{array}$ & $\begin{array}{l}\text { For } \\
\text { Prescribed } \\
\text { Dose } 60 \\
\text { Gy/25 }\end{array}$ & $\begin{array}{l}\text { Within } \\
\text { Suggested } \\
\text { Limit }\end{array}$ & $\begin{array}{l}\text { Dose } \\
\text { Actually } \\
\text { Received by } \\
\text { Temporal } \\
\text { Lobe }\end{array}$ & $\begin{array}{l}\text { Within } \\
\text { Suggested } \\
\text { Limit }\end{array}$ \\
\hline $\begin{array}{l}\text { Emami, et al. } \\
\text { (1991) [9] }\end{array}$ & Review & Mixed & $\begin{array}{l}1 / 3^{\text {rd }} \text { brain } \\
\text { receiving } 60 \text { Gy }\end{array}$ & $5 \%$ at 5 yrs & $\begin{array}{l}<1 \% \\
\text { brain } \\
\text { receiving } \\
60 \mathrm{~Gy}\end{array}$ & Yes & $\begin{array}{l}\text { 1/3rd brain } \\
\text { received } \\
11.5 \text { Gy }\end{array}$ & Yes \\
\hline $\begin{array}{l}\text { Lawrence, et } \\
\text { al. (2010) } \\
\text { (QUANTEC) } \\
\text { [10] }\end{array}$ & 4675 & Mixed & $\begin{array}{l}\text { Fraction size < } \\
2.5 \text { Gy Dmax < } \\
120 \mathrm{~Gy}_{3}(100-140 \\
\left.\mathrm{Gy}_{3}\right)\end{array}$ & $5 \%$ overall & $108 \mathrm{~Gy}_{3}$ & Yes & $83.3 \mathrm{~Gy}_{3}$ & Yes \\
\hline Lee, et al. & & Nasopharyngeal & EQD2 $\leq 64$ & $\begin{array}{l}5 \% \text { at } 10 \\
\text { years }\end{array}$ & 64.8 Gy & Almost & EQD2 50Gy & Yes \\
\hline (1998) [3] & & Carcınoma & Dmax $<104 \mathrm{~Gy}_{3}$ & $\begin{array}{l}5 \% \text { at } 10 \\
\text { years }\end{array}$ & $108 \mathrm{~Gy}_{3}$ & Almost & $\begin{array}{l}\text { Dmax } 108 \\
\mathrm{~Gy}_{3}\end{array}$ & Almost \\
\hline \multirow[t]{2}{*}{$\begin{array}{l}\text { Su, et al. } \\
(2013)[11]\end{array}$} & \multirow[t]{2}{*}{870} & \multirow[t]{2}{*}{$\begin{array}{l}\text { Nasopharyngeal } \\
\text { Carcinoma }\end{array}$} & $r V 40^{a}<10 \%$ & $\begin{array}{l}\text { TLN }^{\mathrm{b}} \\
\text { probability } \\
<2.5 \%\end{array}$ & rV40a $49 \%$ & No & rV40a $49 \%$ & No \\
\hline & & & $\operatorname{aV} 40^{c}<5 c c$ & $\operatorname{aV} 40^{c} 43 \mathrm{cc}$ & & No & $\operatorname{aV} 40^{c} 43 \mathrm{cc}$ & No \\
\hline \multirow[t]{2}{*}{$\begin{array}{l}\text { Jeremy, et al. } \\
(2006) \text { [2] }\end{array}$} & 426 & $\begin{array}{l}\text { Primary Brain } \\
\text { Tumor/Pituitary } \\
\text { Adenoma }\end{array}$ & $\mathrm{BED}^{\mathrm{d}}<85.5 \mathrm{~Gy}_{2}$ & $6 \%$ overall & $132 \mathrm{~Gy}_{2}$ & No & $\begin{array}{l}\mathrm{BED}^{\mathrm{d}} \\
100 \mathrm{~Gy}_{2}\end{array}$ & Yes \\
\hline & & & Dmax $\geq 45$ Gy & $5 \%$ & $\begin{array}{l}\text { Dmax } 61 \\
\text { Gy }\end{array}$ & No & Dmax 61 Gy & No \\
\hline
\end{tabular}




\section{Cureus}

\begin{tabular}{|c|c|c|c|c|c|c|c|c|}
\hline $\begin{array}{l}\text { Marks, et al. } \\
\text { (1981) [12] }\end{array}$ & 152 & $\begin{array}{l}\text { Primary Brain } \\
\text { Tumor/Pituitary } \\
\text { Adenoma }\end{array}$ & $\mathrm{BED}^{\mathrm{d}}<86.4 \mathrm{~Gy}_{3}$ & $\mathrm{TLN}^{\mathrm{b}}$ unlikely & $108 \mathrm{~Gy}_{3}$ & No & $\begin{array}{l}\mathrm{BED}^{\mathrm{d}} 83.3 \\
\mathrm{~Gy}_{3}\end{array}$ & Yes \\
\hline & & & Dmax $\geq 62.5$ Gy & $25 \%$ at $5 \mathrm{yrs}$ & $\begin{array}{l}\text { Dmax } 61 \\
\text { Gy }\end{array}$ & Yes & Dmax 61 Gy & Yes \\
\hline $\begin{array}{l}\text { Lee, et al. } \\
(2002)[1]\end{array}$ & 89 & $\begin{array}{l}\text { Nasopharyngeal } \\
\text { Carcinoma }\end{array}$ & $\begin{array}{l}60 \text { Gy/25\# over } 5 \\
\text { weeks }\end{array}$ & $\begin{array}{l}2.3 \% \text { at } 5 \\
\text { yrs }\end{array}$ & 64.8 Gy & Yes & $\begin{array}{l}50 \mathrm{~Gy} / 25 \# \\
\text { over } 5 \text { weeks }\end{array}$ & Yes \\
\hline $\begin{array}{l}\text { Sheline, et al. } \\
\text { (1980) [13] }\end{array}$ & 80 & Mixed & Dmax $\leq 52$ Gy & TLN $^{\mathrm{b}}$ unlikely & $\begin{array}{l}\text { Dmax } 61 \\
\text { Gy }\end{array}$ & No & Dmax 61 Gy & No \\
\hline $\begin{array}{l}\text { Haberer, et al. } \\
(2010)[14]\end{array}$ & Review & Mixed & $\begin{array}{l}1 / 3^{\text {rd }} \text { Brain } \\
\text { receiving } 60 \text { Gy }\end{array}$ & $5 \%$ at $5 \mathrm{yrs}$ & $\begin{array}{l}<1 \% \text { Brain } \\
\text { receiving } \\
60 \mathrm{~Gy}\end{array}$ & Yes & $\begin{array}{l}<1 \% \text { Brain } \\
\text { receiving } \\
60 \mathrm{~Gy}\end{array}$ & Yes \\
\hline $\begin{array}{l}\text { Sun, et al. } \\
\text { (2013) [15] }\end{array}$ & 20 & $\begin{array}{l}\text { Nasopharyngeal } \\
\text { Carcinoma }\end{array}$ & $\mathrm{D}_{0.5 \mathrm{cc}} \leq 69 \mathrm{~Gy}$ & TLN $^{\mathrm{b}}$ unlikely & $\begin{array}{l}\text { Dmax } 61 \\
\text { Gy }\end{array}$ & Yes & Dmax 61 Gy & Yes \\
\hline
\end{tabular}

\section{TABLE 1: Review of suggested dose constraints in literature, and comparison with dose received by our patient}

a: rV40, Percentage of Temporal Lobe Receiving $\geq 40$ Gy, b: TLN, Temporal Lobe Necrosis, c: aV40, Absolute Volume of Temporal Lobe Receiving $\geq 40$ Gy, d: BED, Biologically Equivalent Dose.

It was interesting to note that despite a prescribed dose to planning target volume (PTV) of 60 $\mathrm{Gy} / 25$, the dose received by the brain parenchyma was about $50 \mathrm{~Gy} / 25$ or less (Figure $3 \mathrm{H}$ ). The contralateral temporal lobe received doses less than $10 \mathrm{~Gy}$ and yet showed subtle features of radionecrosis. On comparing dosimetric data of our patient (both ipsilateral and contralateral temporal lobes) with the recommendations made by various authors in Table 1 , we understand that this patient probably had higher inherent radiosensitivity to experience temporal lobe necrosis at low doses that are considered safe in the absence of concurrent chemotherapy. Another explanation would be damage to the subventricular and subgranular zone stem cell niche which helps in regeneration of neurons and glia [16]. This is substantiated by the extent of necrosis closely following the $40 \mathrm{~Gy}$ isodose distributions. For $40 \mathrm{~Gy} / 25$ in five weeks, the equivalent dose of $2 \mathrm{~Gy}$ (EQD2) is $36 \mathrm{~Gy}_{3}$ or $36.8 \mathrm{~Gy}_{2}$ with a BED of $61.3 \mathrm{~Gy}_{3}$ or $72 \mathrm{~Gy}_{2}$. Most of the brain parenchyma that underwent necrosis received $50 \mathrm{~Gy} / 25$ \# (EQD2:50Gy, BED: $100 \mathrm{~Gy}_{2}$ or $83.3 \mathrm{~Gy}_{3}$ ) and, hence, comparisons in the table have also been made with this in perspective.

Our plan met the dose constraints provided by most authors, except Sheline, et al. and Su, et al. Recommendations made by $\mathrm{Su}$, et al. are based on dosimetry from nasopharyngeal carcinoma series and, hence, may be impractical to adhere to when treating primary brain tumors [11]. However, they can be referred to when treating extracranial cancers. Figure 5 shows that the temporal lobe dose volume histogram (DVH) of our patient was significantly different than the newer guide suggested by Sun, et al. [15]. It is recommended that more conformal forms of therapy like intensity-modulated radiotherapy (IMRT) be utilized to achieve the strict dose constraints suggested by various authors in literature. Treatment with arcs (volumetric modulated arc therapy/ tomotherapy) would have resulted in better sparing of underlying brain parenchyma for superficial tumors like that of our patient's. 


\section{Cureus}

DVH of patient with Temporal Lobe Irradiation Tolerance Curve

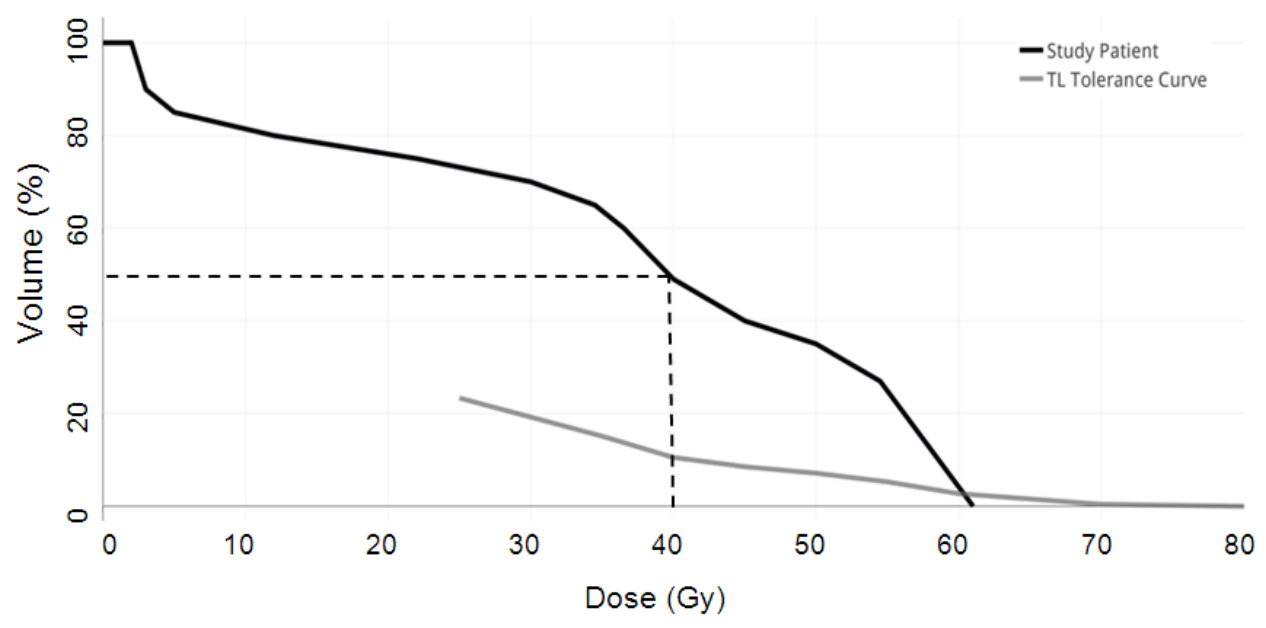

FIGURE 5: Dose volume histogram (DVH) of our study patient overlaid with the temporal lobe irradiation Tolerance curve

By Sun, et al. [15]. DVH of our patient shows that $50 \%$ of the temporal lobe received $\leq 40 \mathrm{~Gy}$, whereas tolerance curve suggests restricting the volume of temporal lobes receiving doses higher than 40 Gy to $<10 \%$.

\section{Conclusions}

In the case presented above, TLN was incidentally diagnosed. The abnormality on the scan led to a detailed central-nervous-system-specific enquiry of symptoms. A detailed history with directed neurological examination may aid in earlier detection. It is important to understand that TLN may occur at lower doses than suggested and in treatment of other cancers than those frequently associated with it. The dose recommendations do not take into consideration the effect of concurrent chemotherapy on radiosensitivity of the brain parenchyma. Our patient was fortunate to have mild symptoms not significantly impacting his quality of life. However, there are many who tend to develop severe symptoms and in such cases early diagnosis and treatment of TLN may prevent clinical progression. Restricting doses to brain to as low as reasonably achievable is the key to preventing TLN.

\section{Additional Information}

\section{Disclosures}

Human subjects: Consent was obtained by all participants in this study. Conflicts of interest: In compliance with the ICMJE uniform disclosure form, all authors declare the following: Payment/services info: All authors have declared that no financial support was received from any organization for the submitted work. Financial relationships: All authors have declared that they have no financial relationships at present or within the previous three years with any organizations that might have an interest in the submitted work. Other relationships: All authors have declared that there are no other relationships or activities that could appear to have influenced the submitted work.

\section{References}

1. Lee AWM, Kwong DLW, Leung SF, Tung SY, Sze WM, Sham JST, Teo PML, Leung TW, Wu PM, 
Chappell R, Peters LJ, Fowler JF: Factors affecting risk of symptomatic temporal lobe necrosis: significance of fractional dose and treatment time. Int J Radiat Oncol Biol Phys. 2002, 53:7585. 10.1016/S0360-3016(02)02711-6

2. Ruben JD, Dally M, Bailey M, Smith R, McLean CA, Fedele P: Cerebral radiation necrosis: incidence, outcomes, and risk factors with emphasis on radiation parameters and chemotherapy. Int J Radiation Oncology Biol Phys. 2006, 65:499-508.

10.1016/j.ijrobp.2005.12.002

3. Lee AWM, Foo W, Chappell R, Fowler JF, Sze WM, Poon YF: Effect of time, dose, and fractionation on temporal lobe necrosis following radiotherapy for nasopharyngeal carcinoma. Int J Radiat Oncol Biol Phys. 1998, 40:35-42. 10.1016/S0360-3016(97)00580-4

4. Dassarath M, Yin Z, Chen J, Liu H, Yang K, Wu G: Temporal lobe necrosis: a dwindling entity in a patient with nasopharyngeal cancer after radiation therapy. Head Neck Oncol. 2011, 3:8. 10.1186/1758-3284-3-8

5. Chan YL, Leung SF, King AD, Choi PH, Metreweli C: Late radiation injury to the temporal lobes: morphologic evaluation at MR imaging. Radiology. 1999, 213:800-7.

10.1148/radiology.213.3.r99dc07800

6. Wang XL, Yin JL, Li XD, Li X, Ou YX, Zhou Z, Zheng H: PET/CT-based classification of delayed radiation encephalopathy following radiotherapy for nasopharyngeal carcinoma (Article in Chinese). Nan Fang Yi Ke Da Xue Xue Bao. 2008, 28:320-323.

7. Chan AS, Cheung MC, Law SC, Chan JH: Phase II study of alpha-tocopherol in improving the cognitive function of patients with temporal lobe radionecrosis. Cancer. 2004, 100:398-404. 10.1002/cncr.11885

8. Chen J, Dassarath M, Yin Z, Liu H, Yang K, Wu G: Radiation induced temporal lobe necrosis in patients with nasopharyngeal carcinoma: a review of new avenues in its management. Radiat Oncol. 2011, 6:128. 10.1186/1748-717X-6-128

9. Emami B, Lyman J, Brown A, Cola L, Goitein M, Munzenrider JE, et al: Tolerance of normal tissue to therapeutic irradiation. Int J Radiat Oncol. 1991, 21:109-22. 10.1016/03603016(91)90171-Y

10. Lawrence YR, Li XA, el Naqa I, Hahn CA: Radiation dose-volume effects in the brain. Int J Radiation Oncology Biol Phys. 2010, 76:S20-S27. 10.1016/j.ijrobp.2009.02.091

11. Su SF, Huang SM, Han F, Huang Y, Chen CY, Xiao WW, Sun XM, Lu TX: Analysis of dosimetric factors associated with temporal lobe necrosis (TLN) in patients with nasopharyngeal carcinoma (NPC) after intensity modulated radiotherapy. Radiat Oncol. 2013, 8:17. 10.1186/1748-717X-8-17

12. Marks JE, BagÍan RJ, Prassad SC, Blank WF: Cerebral radionecrosis: incidence and risk in relation to dose, time, fractionation and volume. Int J Radiat Oncol Biol Phys. 1981, 7:243252. 10.1016/0360-3016(81)90443-0

13. Sheline GE, Wara WM, Smith V: Therapeutic irradiation and brain injury. Int J Radiat Oncol Biol Phys. 1980, 6:1215-1228. 10.1016/0360-3016(80)90175-3

14. Haberer S, Assouline A, Mazeron JJ: Normal tissue tolerance to external beam radiation therapy: brain and hypophysis (Article in French). Cancer/Radiothérapie. 2010, 14:263-268. 10.1016/j.canrad.2010.02.005

15. Sun Y, Zhou GQ, Qi ZY, Zhang L, Huang SM, Liu LZ, Li L, Lin AH, Ma J: Radiation-induced temporal lobe injury after intensity modulated radiotherapy in nasopharyngeal carcinoma patients: a dose-volume-outcome analysis. Cancer. 2013, 13:397. 10.1186/1471-2407-13-397

16. Kut C, Redmond KJ: New considerations in radiation treatment planning for brain tumors: neural progenitor cell-containing niches. Semin Radiat Oncol. 2014, 24:265-272.

10.1016/j.semradonc.2014.06.007 